\title{
Cerebral Venous Thrombosis: A Comprehensive Review
}

\author{
Pretty Sara Idiculla ${ }^{a}$ Dhineshreddy Gurala ${ }^{b}$ Manikandan Palanisamy ${ }^{c}$ \\ Rajendran Vijayakumar ${ }^{c}$ Sindhu Dhandapani ${ }^{d}$ Elanagan Nagarajan ${ }^{e}$ \\ aUniversity of Missouri Health Care, Columbia, MO, USA; ${ }^{b}$ Staten Island University Hospital, Northwell Health, \\ Staten Island, NY, USA; 'Majmaah University, Industrial Area, Al Majma'ah, Saudi Arabia; \\ ${ }^{\mathrm{d} C}$ ure Hospital, Vellakovil, India; ${ }^{e}$ Columbia University Medical Center, New York, NY, USA
}

\section{Keywords}

Cerebral venous thrombosis - Dural sinus thrombosis .

Magnetic resonance venogram

\begin{abstract}
Background: Cerebral sinus venous thrombosis (CSVT) is a relatively rare, potentially fatal neurological condition that can be frequently overlooked due to the vague nature of its clinical and radiological presentation. A literature search on PubMed using the keyword "Cerebral sinus venous thrombosis" was performed. We searched for the epidemiology, risk factors, pathophysiology, clinical features, diagnosis, and treatment of CSVT. All full-text articles in the last 10 years, in adults ( $>18$ years), and the English language were included. We aim to give a comprehensive review of CSVT, with a primary focus on the management of the disease. Summary: The literature search revealed 404 articles that met our criteria. CSVT is a relatively rare condition that accounts for approximately $1 \%$ of all forms of stroke. They can be subdivided into acute, subacute, and chronic forms based on the time of onset of clinical symptoms. It is a multifactorial disease, and the major forms of clinical presentation include isolated intracranial hypertension syndrome, focal
\end{abstract}

neurological deficits, and cavernous sinus syndrome. MRI with magnetic resonance venogram (MRV) is considered the gold standard for diagnosis. Anticoagulation with heparin or low-molecular-weight heparin is the mainstay of treatment. Endovascular management is indicated for those cases with severe symptoms or worsening of symptoms despite anticoagulation therapy. Favorable outcomes have been reported in patients who receive early diagnosis and treatment. Conclusion: CSVT is a potentially fatal neurological condition that is often under-diagnosed due to its nonspecific presentation. Timely diagnosis and treatment can reduce morbidity and mortality, remarkably improving the outcome in affected individuals.

(c) 2020 S. Karger AG, Basel

\section{Introduction}

Cerebral sinus venous thrombosis (CSVT) is a rare form of stroke associated with an increased mortality rate. It can present with a multitude of signs and symptoms, making it difficult to distinguish from other neurological conditions. Early recognition of symptoms and treatment improves overall outcome in these patients. 
CSVT demands a close functioning of both clinical and radiological proficiency for prompt detection and optimizing patient care.

\section{Method and Results}

A literature search was done on PubMed using the keyword "Cerebral sinus venous thrombosis". We searched for the epidemiology, risk factors, pathophysiology, clinical features, diagnosis, and treatment of CSVT. All full-text articles in the last 10 years, in adults (>18 years), and in the English language were included. Case reports, case series, review articles, and observational studies with relevant documentation were analyzed for our review. The literature search revealed 404 articles that met our criteria. Our aim is to give a comprehensive review on CSVT, with primary focus on the management of the disease in adults.

\section{Definition}

CSVT is a rare form of venous thromboembolism (VTE) and based on the time of onset of clinical symptoms. There are 3 subtypes [1]:

1. Acute $-\leq 48 \mathrm{~h}$.

2. Subacute $->48 \mathrm{~h}-\leq 30$ days.

3. Chronic $-\geq 1$ month.

\section{Epidemiology}

The incidence of CSVT has increased over the past few years due to the advancement of imaging techniques helping detection of the disease in its early stages. Although the autopsy series approximates the incidence to be 3-4 cases per million, clinical series have shown a 10-fold increase in these numbers [2]. An increased incidence is seen among children, younger adults, females of the reproductive age-group, and lowincome countries [3]. The estimated female-to-male ratio was $3: 1$ and comprises $0.5-1 \%$ of all stroke occurrences $[4,5]$.

The most common form of CSVT is the subacute type, which constitutes almost half of all the cases, and the chronic form is less frequent [6]. The ISCVT (International Study on Cerebral Vein and Dural Sinus Thrombosis) determined the occurrence of CSVT in various sites - transverse sinus (86\%), superior sagittal sinus (62\%), straight sinus (18\%), cortical veins (17\%), jugular veins $(12 \%)$, vein of Galen, and internal cerebral vein (11\%) [6].

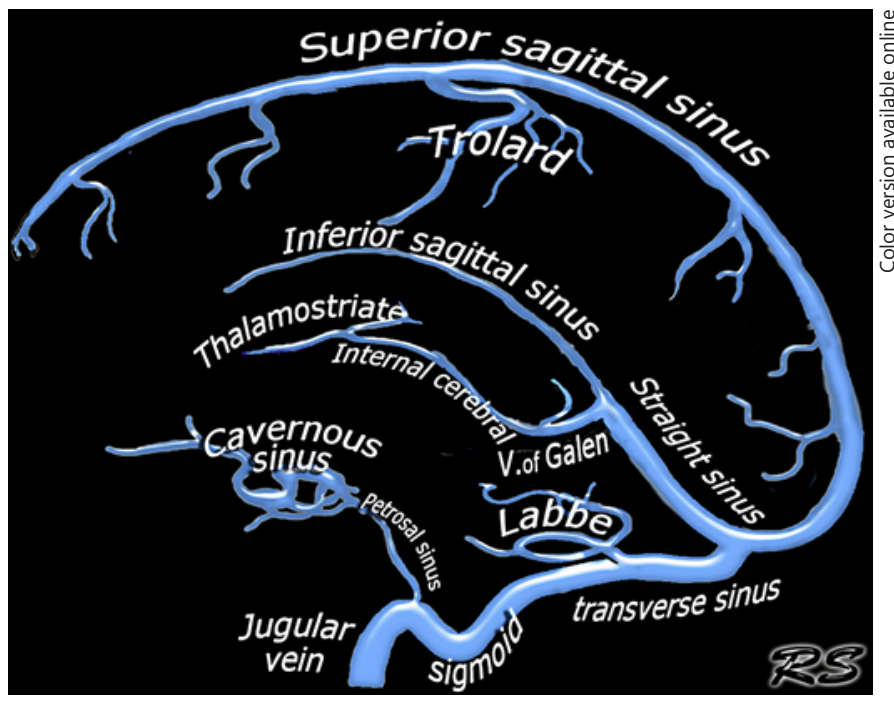

Fig. 1. Anatomy of cerebral venous system. The figure was reproduced with permission from the Radiology Assistant Web site (http://www.radiologyassistant.nl/en/p4befacb3e4691/cerebralvenous-thrombosis.html).

\section{Anatomy of the Cerebral Venous System}

Cerebral venous system is divided into the superficial and deep venous system [7-9]. They are a group of venous channels located intracranially between the endosteal and meningeal layers of the dura mater. Unlike systemic veins, cerebral veins lack valves and do not follow cerebral arterial territory. The superior sagittal sinus, in particular, also drains the cerebrospinal fluid from the subarachnoid space.

The superficial system comprises the dural sinuses and cortical veins. It drains the cerebral cortex and superficial white matter. The 2 major dural sinuses include the superior sagittal sinus that drain dorsolateral area and the cavernous sinus that drain the anteroventral region. The superior sagittal sinus drains into the transverse sinus which then drains into the straight sinus. The cavernous sinus drains into the transverse sinus posterolaterally and sigmoid sinus inferolaterally, along the superior and inferior petrosal sinuses, respectively. The superficial cortical veins are the superiorly draining veins and the inferiorly draining veins (vein of Labbe and sylvian or superficial middle cerebral veins).

The deep system includes straight, lateral, and sigmoid sinus, as well as drain the deeper cortical veins (vein of Galen, internal cerebral veins, Rosenthal or basal vein, medullary, and subependymal veins). These vessels drain the basal ganglia, thalamus, the upper brain stem, and 
Table 1. Risk factors for CVT [10]

\begin{tabular}{|c|c|}
\hline Risk factor & Description \\
\hline \multirow[t]{2}{*}{$\begin{array}{l}\text { Prothrombotic } \\
\text { conditions }\end{array}$} & $\begin{array}{l}\text { Hereditary: factor V Leiden mutation, } \\
\text { antithrombin III deficiency, protein C/S } \\
\text { deficiency, and G20210A prothrombin gene } \\
\text { mutation }\end{array}$ \\
\hline & $\begin{array}{l}\text { Acquired: These are transient forms and are } \\
\text { considered specific to females. It includes } \\
\text { pregnancy, puerperium, oral contraceptive pill } \\
\text { use, and hormonal replacement therapy }\end{array}$ \\
\hline \multirow[t]{3}{*}{ Infections } & Intracranial: meningitis \\
\hline & Systemic: HIV, tuberculosis, and sepsis \\
\hline & $\begin{array}{l}\text { Local: otitis media, mastoiditis, oral, sinus, and } \\
\text { head and neck infections }\end{array}$ \\
\hline \multirow{4}{*}{$\begin{array}{l}\text { Mechanical } \\
\text { trauma }\end{array}$} & Head trauma \\
\hline & Neurosurgical procedures \\
\hline & Jugular vein catheterization \\
\hline & LP \\
\hline \multirow[t]{7}{*}{ Vasculitis } & Systemic lupus erythematosus \\
\hline & Sjogren's syndrome \\
\hline & Temporal arteritis \\
\hline & Antiphospholipid syndrome \\
\hline & Thromboangitis obliterans \\
\hline & Wegener's granulomatosis \\
\hline & Behcet's disease \\
\hline
\end{tabular}

deep brain white matter. Both the superficial and deep venous systems eventually drain into the internal jugular veins (Fig. 1).

\section{Risk Factors}

CSVT is a multifactorial disease with at least one risk factor implicated in $85 \%$ of affected adults [6] (Table 1). These risk factors are usually always associated with thrombogenic triad of Virchow, which includes vessel wall injury, blood stasis, and hypercoagulability [5]. Prothrombotic conditions are the most common implicated risk factor for CVT. Patients with hereditary thrombophilia have an increased predisposition for developing any form of thrombosis, including CSVT. G20210A prothrombin polymorphism, factor $\mathrm{V}$ Leiden, and antiphospholipid syndrome are most frequent causes. Protein C,

\begin{tabular}{|c|c|}
\hline Risk factor & Description \\
\hline \multirow{4}{*}{$\begin{array}{l}\text { Intracranial } \\
\text { defects }\end{array}$} & Tumors \\
\hline & Arteriovenous malformations \\
\hline & Dural fistula \\
\hline & Venous anomalies \\
\hline \multirow[t]{4}{*}{ Hematological } & Essential thrombocythemia \\
\hline & Myeloproliferative malignancies \\
\hline & Primary and secondary polycythemia \\
\hline & Paroxysmal nocturnal hemoglobinuria \\
\hline \multirow{7}{*}{$\begin{array}{l}\text { Systemic } \\
\text { diseases }\end{array}$} & Dehydration \\
\hline & Malignancies \\
\hline & Thyroid disease \\
\hline & Sarcoidosis \\
\hline & Obesity \\
\hline & Nephrotic syndrome \\
\hline & Inflammatory bowel disease \\
\hline \multirow[t]{4}{*}{ Drugs } & $\begin{array}{l}\text { Hormone therapy: tamoxifen, glucocorticoids, } \\
\text { and androgens }\end{array}$ \\
\hline & Inhibitors of angiogenesis: thalidomide \\
\hline & Hemostatic therapy \\
\hline & Chemotherapy: cyclosporine and 1-asparaginase \\
\hline
\end{tabular}

S deficiency, and antithrombin III deficiency are less commonly encountered risk factors [10].

A prospective study involving 465 women found that $65 \%$ of cases had some form of risk factors like pregnancy, puerperium, oral contraceptive pill (OCP) use, and hormonal replacement therapy associated with CSVT [11]. Studies also show that these gender-specific risk factors are not applicable to the pediatric or elderly population $[12,13]$. A meta-analysis has shown that OCP users have 6 times higher risk of developing CSVT than non-users. The same study also concluded an increased risk of CSVT in patients with G20210A prothrombin polymorphism, factor V Leiden deficiency, and hyperhomocysteinemia [14]. Studies also show an increased risk of CSVT in OCP users who are overweight or obese and are carriers of hereditary thrombophilia $[15,16]$.

Local head and neck infections are the most common infectious cause of CSVT, and studies have shown that it 


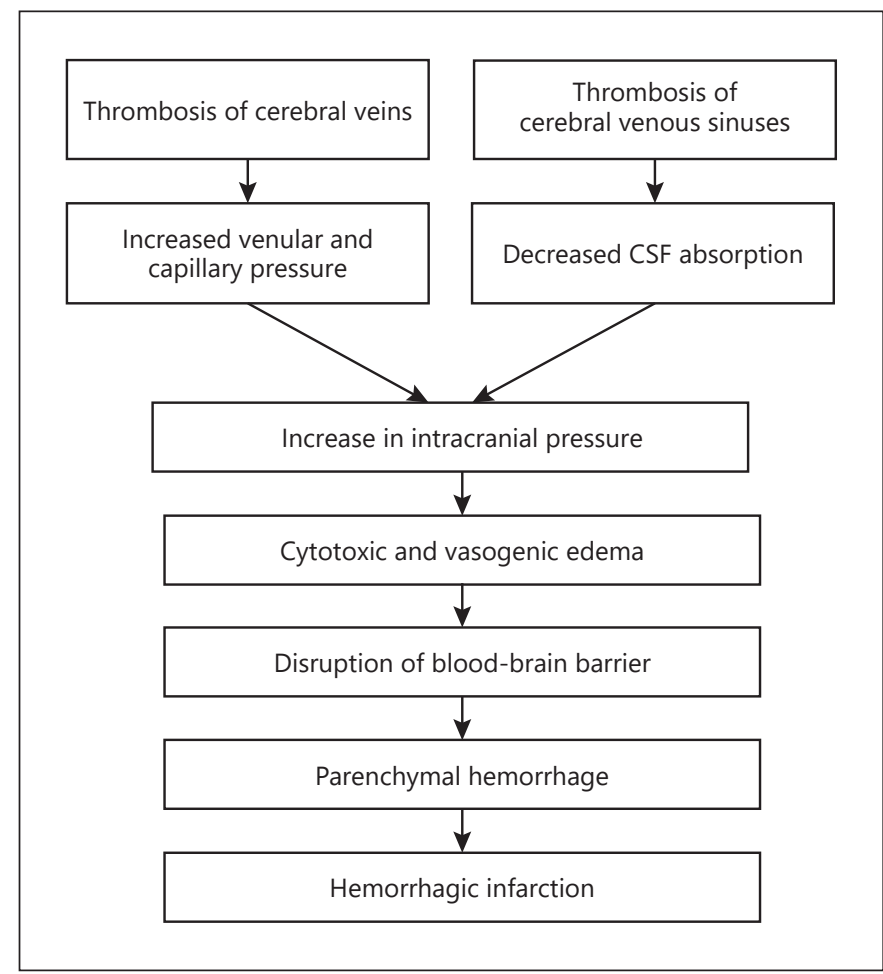

Fig. 2. Pathophysiology of CVT [22]. CSF, cerebrospinal fluid.

is more common in lesser developed countries [17, 18]. Intracranial neoplasm can result in CSVT due to local compression or tumor invasion of the sinus [19]. A retrospective study conducted in a tertiary center involving 90 CSVT patients showed that $14 \%$ of their patients had a history of some form of head trauma prior to the diagnosis, $7 \%$ of affected individuals had head and neck infections, and $8 \%$ had brain tumors [20].

\section{Pathophysiology}

The pathophysiological mechanisms of CVT are not fully understood and are a complex mix of changes in hemodynamics and brain parenchyma [21]. The current knowledge of the CVT pathophysiology is based on available animal model studies. The clinical presentation of CVT can be explained by 2 pathological mechanisms thrombosis of cerebral veins and thrombosis of cerebral venous sinuses (Fig. 2).

Animal model studies have shown that sinus thrombosis leads to sinus occlusion and backflow of blood into venules and capillaries, resulting in increased local pressure, eventually resulting in massive cerebral edema [23].
Extensive anastomoses found within the cerebral venous system often allow the development of collateral circulation if there is an occlusion to venous flow. Cortical vein occlusion can result in increased small vessel pressure, depending on the extent of thrombosis and availability of collaterals. This can further lead to disruption of the blood-brain barrier, leakage of blood components into the interstitial space causing vasogenic edema, and parenchymal tissue damage [24].

Decrease in the cerebrospinal fluid drainage due to sinus occlusion can result from the dysfunction of arachnoid granulations, causing an increase in intracranial pressure. A continuous rise in pressure results in capillary hypertension, cerebral edema, and venous hemorrhage [25]. This further results in a decrease in the cerebral perfusion pressure and metabolic failure, followed by intracellular edema and cytotoxic edema [26].

\section{Clinical Features}

The clinical presentation of CVT is often variable, and patients may present with a constellation of symptoms depending on the site and extent of thrombosis, patient's age, and the underlying etiological factors. The most common presentation includes signs of raised intracranial pressure such as headache, reduced visual acuity, and papilledema, focal neurological deficits, seizures, and diffuse encephalopathy. Other uncommon presentations include subarachnoid hemorrhage, thunderclap headache, recurrent transient ischemic attacks, tinnitus, isolated headache, and multiple cranial nerve palsies in the setting of cavernous sinus thrombosis [4].

\section{Headache}

Headache is one of the most common presentations and is seen in more than $80 \%$ of patients with CSVT [27]. Patients with headache often present in isolation or associated with other signs and symptoms such as vomiting, papilledema, visual field defects, vision loss, tinnitus, as well as abducens nerve palsy. Vision loss and papilledema is usually seen in patients with a chronic onset [10]. Studies have shown that CVT patients can present with isolated headache without any evidence of raised intracranial hypertension and is frequently seen in patients who seek early medical attention [28]. Headache due to raised intracranial pressure can occur as a result of large venous sinus thrombosis like sagittal sinus. These patients present with sudden, severe, generalized, and progressive headache that worsens with Valsalva, straining, and lying 
down [29]. Some individuals may develop a sudden, severe, explosive form called thunderclap headache that mimic subarachnoid hemorrhage [30]. With the involvement of the lateral sinus, patients can have raised intracranial pressure and symptoms similar to a middle ear infection like fever, ear discharge, headache, and pain over the mastoid region [31].

\section{Focal Neurological Deficits}

The most common form of deficit is motor weakness seen in the form of monoparesis, hemiparesis, or bilateral involvement in patients with deep venous system thrombosis. Though motor involvement is common, these patients rarely have visual or sensory deficits [32]. Thrombosis of the cavernous sinus is usually associated with infection and affects extra ocular movements due to the involvement of oculomotor, abducent, and/or trochlear nerves. They present with headache, eye pain, constitutional symptoms, proptosis, chemosis, periorbital edema, and paralysis of eye movements [33].

\section{Seizures}

Seizures are a common presentation in patients with CSVT, especially in the acute phase of the disease [33]. It is more common in patients with hemorrhagic supratentorial lesions, superior sagittal sinus or cortical vein thrombosis, and in patients with focal neurological deficits [10]. A prospective study of 194 patients with acute CVT found early symptomatic seizures in $44.3 \%$ patients and status epilepticus in $12.8 \%$ patients. They also found a high incidence of Todd's paresis associated with seizures [34].

\section{Diffuse Encephalopathy}

It is a more severe presentation of CSVT and individuals with deep venous system affection may develop encephalopathy resulting in an alteration of consciousness, mental status changes, delirium, apathy, or dysexecutive symptoms. These patients can also develop bilateral or multifocal deficits or present with seizures. Encephalopathy is a common occurrence among the elderly population [12].

ISCVT summarized the occurrence of clinical manifestations - progressively worsening headache (most common symptom $-88.8 \%$ ), seizures $(39.3 \%)$, paresis $(37.2 \%)$, papilledema $(28.3 \%)$, altered mental status (22\%), aphasia (19.1\%), stupor or coma (13.9\%), diplopia (13.5\%), and visual field defects (13.2\%) [6]. Left transverse sinus involvement may present with aphasia and sagittal sinus involvement can result in unilateral or bilat- eral motor deficits and focal or generalized seizures [22]. Isolated cortical vein thrombosis presents with headache, seizures, and focal neurological deficits [10]. Deep venous system thrombosis results in centrally located, bilateral thalamic lesions that presents with behavioral manifestations like amnesia, delirium, and mutism [35]. Cerebral herniation can result from diencephalon or brain stem compression due to large unilateral infarcts or hemorrhages. Coma can occur due to involvement of the brain stem, thalamus, or from generalized seizures [33].

\section{Diagnosis}

The wide variety of clinical presentations makes it particularly difficult for the diagnosis of CSVT. A high index of suspicion and appropriate clinical acumen is essential for the detection of affected individuals.

\section{Laboratory Tests}

CSVT patients should have a panel of tests done, including complete blood count, comprehensive metabolic panel, and a coagulation profile. These tests help identify associated etiological risk factors of CVT [36]. A lumbar puncture (LP) can be performed to rule out other causes like intracranial infections [36].

\section{Neuroimaging}

Neuroimaging is the gold standard and is ultimately required for diagnosis and localization of CVT. Imaging of the cerebral venous system is recommended in patients with cortical hemorrhage of the unclear origin or with infarction in multiple arterial territories by the American Heart Association (AHA) and American Stroke Association (ASA) [11].

\section{Computed Tomography Scan}

The recommended initial diagnostic imaging is a noncontrast computed tomography (CT) head for all patients presenting with acute neurological complaints such as headache, focal neurological deficits, altered mental status, and seizures [10]. In about $30 \%$ of cases, CT may be normal or show nonspecific abnormalities; thus, a normal scan does not rule out CSVT [37]. Non-contrast CT shows direct signs like dense clot sign (visualization of thrombus in the cerebral veins and sinuses) and string or cord sign (string or cord-like density indicating CSVT); as well as indirect signs like cerebral edema, mass effect, and intracranial hemorrhage that can range from small juxtacortical lesions to subarachnoid hemorrhage and 
Fig. 3. Presentations of CVT on CT head. The figure was reproduced with permission from the Radiology Assistant website (http://www.radiologyassistant.nl/en/ p4befacb3e4691/cerebral-venous-thrombosis.html). a Dense clot sign (blue arrows, dense transverse sinus due to thrombosis). Hemorrhagic infarction of the temporal lobe (red arrow). b Empty delta sign (right and left transverse sinus; and sigmoid sinus thrombosis).

Fig. 4. Time-dependent appearance of thrombus on different sequences of MRI brain. The figure was reproduced with permission from the Radiology Assistant website (http://www.radiologyassistant.nl/en/ p4befacb3e4691/cerebral-venous-thrombosis.html). a T1-weighted images: red arrow, hyperintense signal due to thrombosis. b T2-weighted image: blue arrow, normal flow in right sigmoid sinus and jugular vein; red arrow, hyperintense signal due to thrombosis.
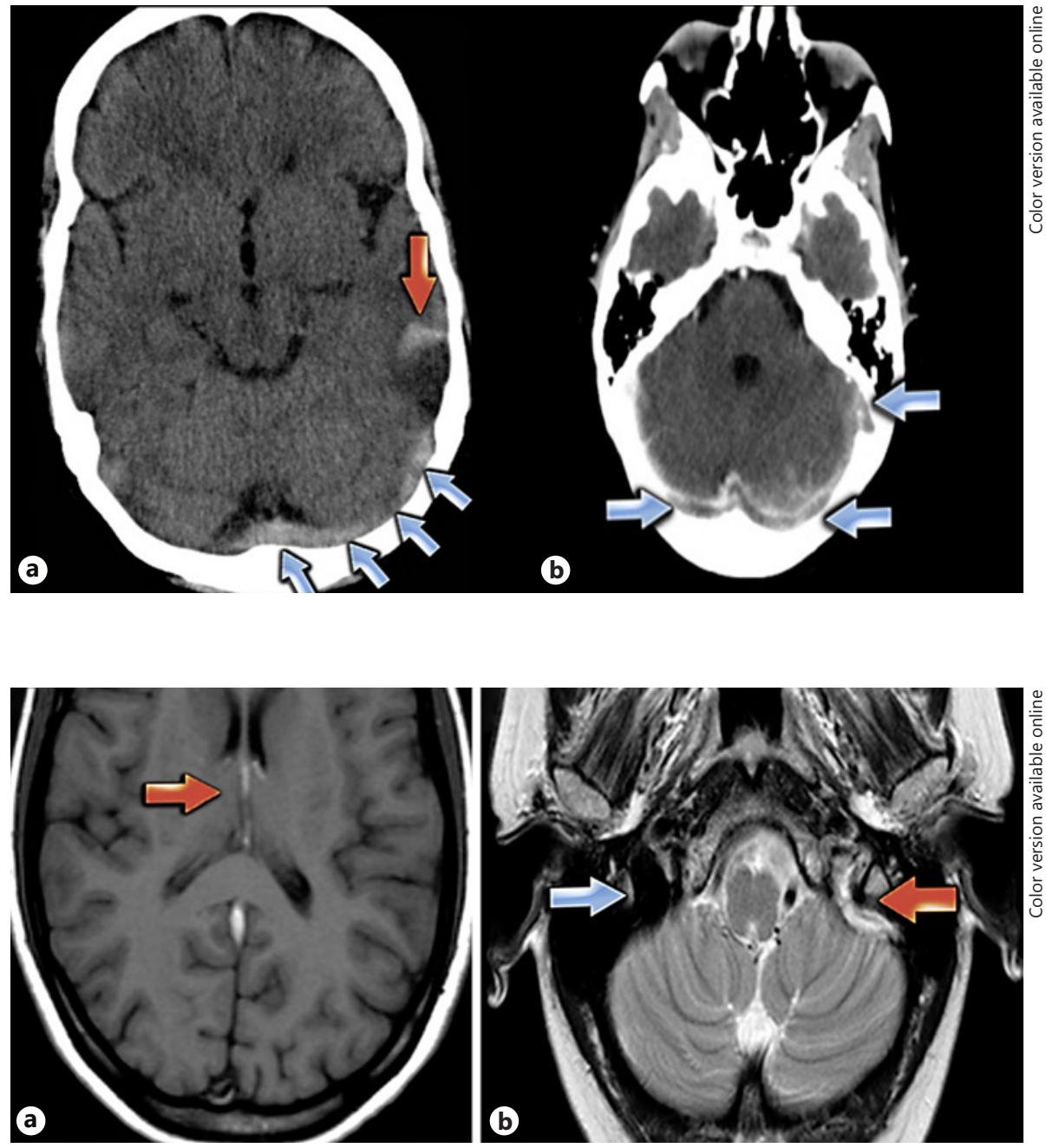

large hemorrhagic infarcts. Contrast-enhanced CT shows direct signs like empty delta sign (a low-attenuated center surrounded by a triangular area of contrast enhancement) and indirect signs, similar to non-contrast CT [38, 39] (Fig. 3).

\section{CT Venography}

Venous enhancement following a CT scan help evaluate filling defects in the cortical sinuses and veins, increased collateral venous drainage, as well as enhancement of sinus walls in these patients [40]. CT venography (CTV) has an overall sensitivity of about $95 \%$ and may be useful for patients with a subacute or chronic presentation [5]. Studies support the use of CTV for the diagnosis of cerebral sinus thrombosis and show it has less diagnostic value for cortical vein thrombosis [41]. CTV is a rapid and reliable option, especially in those patients with contraindication to perform an MRI.

\section{MRI and Magnetic Resonance Venogram}

MRI with contrast and magnetic resonance venogram (MRV) is the most preferred diagnostic modality for CSVT, and the appearance of thrombus on different MRI sequences are time dependent. Within 5 days, it appears isointense on $\mathrm{T} 1$ and hypointense on T2-weighted images. In 6-15 days, thrombus appears hyperintense on both T1 and T2 sequences. After 15 days, they appear isointense on $\mathrm{T} 1$ and iso- or hyperintense on $\mathrm{T} 2$ sequences. Four months later, no abnormalities on $\mathrm{T} 1$ and subtle abnormalities on T2 sequences can be detected [42-44] (Fig. 4). The MRI appearances in the acute form occur due to an increased amount of deoxyhemoglobin in the thrombus, and the changes seen with the subacute form is due to an increased concentration of methemoglobin [8]. The absence of changes in the T1 signal sequence and normal flow pattern on the $\mathrm{T} 2$ sequence makes diagnosis particularly difficult in the acute form of the disease [45]. 
Table 2. Comparing the pros and cons of imaging modalities used in CVT diagnosis $[8,40,42,48]$

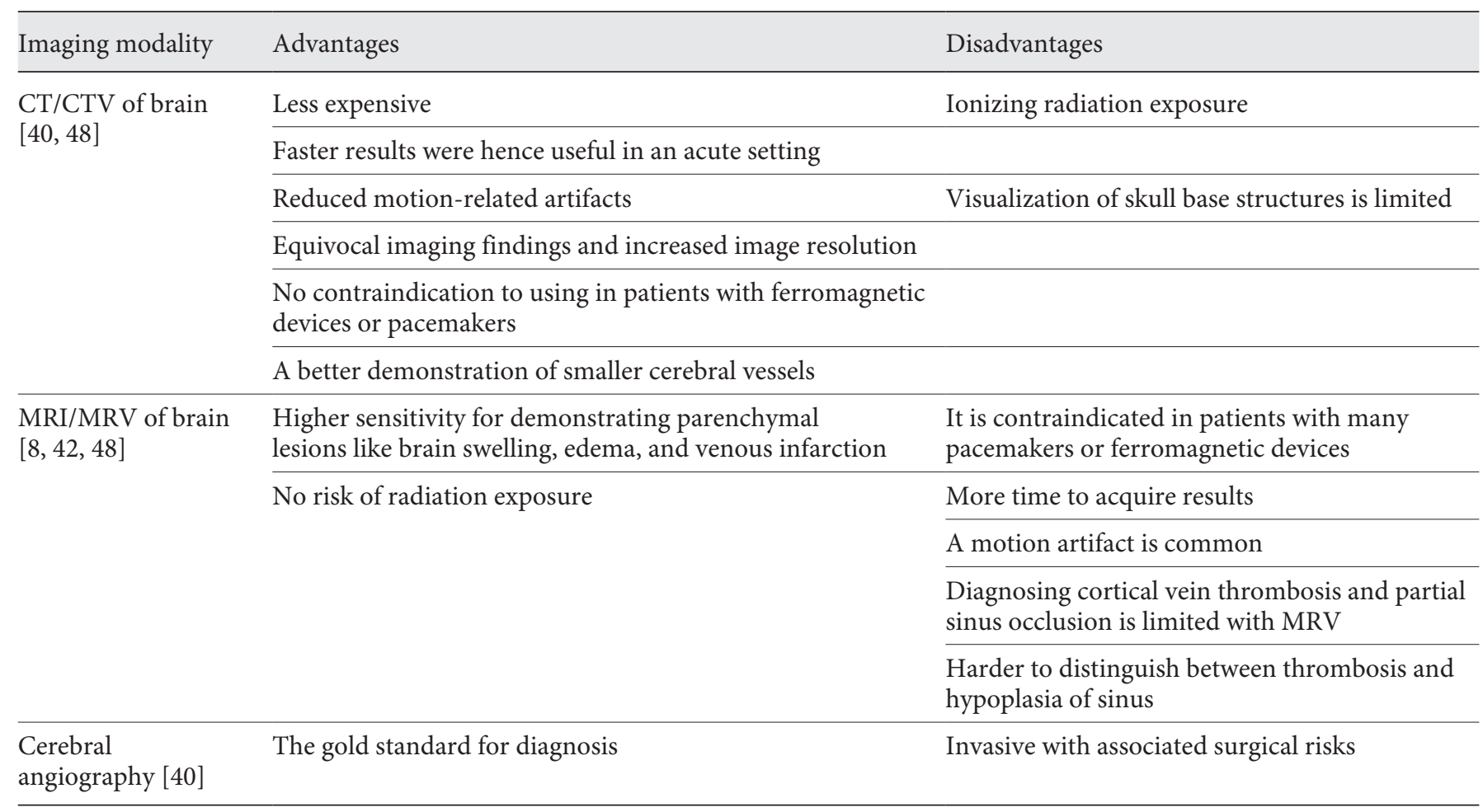

MRV, magnetic resonance venogram; CT, computed tomography; CTV, CT venography.

Gradient-echo T2 and susceptibility-weighted imaging sequences help identify a thrombus as a hypointense area and can be useful in the detection of acute CSVT. Susceptibility-weighted sequences are also beneficial for the diagnosis of an isolated cortical vein involvement [46]. MRV is a noninvasive diagnostic modality used for the diagnosis of CSVT suggested by the absence of normal flow in a vein or sinus. A contrast-enhanced MRV is considered more sensitive to time-of-flight MRV for the detection of thrombus in smaller veins [47].

\section{Digital Subtraction Angiography}

Cerebral angiography was considered the primary diagnostic procedure used for the diagnosis of intracranial venous abnormalities but has very well been replaced by CTV and MRI. It is performed when other imaging modalities are inconclusive or unavailable. Angiography can be challenging to interpret in the presence of anatomic variations like superior sagittal sinus duplication, hypoplasia of the anterior part of superior sagittal sinus, and hypoplasia or aplasia of the transverse sinuses. The usual findings include a partial or complete filling defect in the sinuses or veins, delayed emptying, and dilated collateral circulation. There is an abrupt stopping of cortical veins with surrounding tortuous and dilated collateral "corkscrew" vessels [10].

\section{Advantages and Disadvantages of Diagnostic} Modalities

A comparison of the various imaging modalities including CT/CTV, MRI/MRV, and a digital subtraction angiography is summarized in Table 2.

\section{Treatment}

\section{Anticoagulant Therapy}

Anticoagulant therapy is indicated in CSVT patients to promote clot resolution and prevent clot expansion. Small-scale studies comparing the safety and efficacy of anticoagulation with placebo has shown a clinically favorable trend toward the use of anticoagulants in patients with CSVT [49, 50]. A meta-analysis done with these studies showed a reduction in poor outcome rates in CVT patients treated with unfractionated heparin or low-molecular-weight heparin (LMWH) [51]. The duration of 
anticoagulation, as well as the use of direct oral anticoagulants, is still a controversial topic since no large-scale randomized control trials are available. The 2017 European Stroke Organization guidelines for the diagnosis and treatment of CSVT, endorsed by the European Academy of Neurology, recommend the following for anticoagulation therapy in CSVT [52]:

- Therapeutic dosage of heparin to all patients with acute CVT, even in the presence of intracerebral hemorrhage.

- LMWH over unfractionated heparin except in patients who are allergic to the LMWH or if fast anticoagulant effect reversal is required.

- The AHA/ASA guidelines recommend anticoagulation for 3-6 months in provoked CSVT, 6-12 months in unprovoked CSVT, and potentially lifelong in recurrent CSVT, VTE following CSVT, or CSVT associated with severe thrombophilia with target international normalized ratio of 2-3 [5].

\section{Thrombolysis}

CSVT patients have a favorable clinical outcome with anticoagulant therapy; however, some patients may fail to improve or clinically deteriorate despite treatment. AHA/ ASA suggests that these patients may have an added treatment option of endovascular thrombolysis performed in advanced centers [5]. Thrombolysis aids the dissolution of the clot and reopens occluded cerebral sinus or veins. A systematic review of 15 studies showed that thrombolysis has a significant increase in major bleeding complications associated with it [53]. The thrombolysis or anticoagulation for cerebral venous thrombosis trial is an ongoing multicenter, randomized control study to determine if thrombolysis will improve outcome in severe CVT patients with poor outcome [54]. In the near future, this study may provide a better understanding of the use of thrombolytics in CSVT patients. The British Committee for Standards in Hematology recommends that endovascular thrombolysis be used as a last resort in patients who have a fatal outcome or do not respond to anticoagulant therapy. However, it is not indicated in patients whose deterioration is attributed to intracranial hemorrhage [55].

\section{Symptomatic Therapy}

Symptomatic treatment mainly involves the management of seizures and increased intracranial pressure, which can result in vision loss and headache.

\section{Seizure Control}

Seizures are frequent, affecting up to $50 \%$ of all CVT patients, and the prophylactic use of antiepileptic drugs though favored by some studies, remains controversial [56]. A prospective study identified intracranial hemorrhage, cortical vein thrombosis, and focal neurological deficits as independent predictors of early seizures and suggested that prophylactic antiepileptic therapy may benefit these patients [34]. Another study found focal sensory deficits and admission imaging showing focal edema or infarcts (ischemic/hemorrhagic) as significant predictors of seizures in CVT patients [57]. Several studies have also demonstrated the presence of supratentorial lesion to be a predictor for seizures $[58,59]$. Though the duration of treatment is uncertain, it is recommended to give antiepileptic therapy to acute CSVT patients with seizures and supratentorial lesions to prevent recurrence [52].

\section{Treatment of Raised Intracranial Pressure}

Cerebral edema is common in CSVT patients. However, mild swelling improves with anticoagulant therapy, which dissolves thrombus, improving flow, and thereby reducing intracranial pressure. Patients who develop a headache can be given analgesics for symptomatic relief. Transtentorial herniation of the brain is the most common cause of death in CSVT patients [60]. Carbonic anhydrase inhibitors like acetazolamide help in reducing the intracranial pressure (ICP) and alleviating headache as well as preventing visual damage [61]. The European Federation of Neurological Societies recommends the following [62]:

- LP can be considered before initiation of anticoagulation, in the absence of parenchymal abnormalities (large infarcts or hemorrhages) in patients with intracranial hypertension.

- Acetazolamide may be considered in patients with persistent papilledema.

- In patients with continuing visual deterioration despite repeated LP and Acetazolamide administration, shunting procedures like lumboperitoneal, ventriculoperitoneal shunts, and optic nerve fenestration can be considered.

- Steroid therapy is ineffective due to lack of scientific evidence.

- Anti-edema treatment should be carried out based on the general principles of treatment for raised ICP. These include elevating head at $30^{\circ}$, hyperventilation (target $\mathrm{PaCO}_{2}=30-35 \mathrm{~mm} \mathrm{Hg}$ ), and intravenous administration of osmotic diuretics.

- Decompressive surgery (craniectomy) is recommended in patients with severe thrombosis and with impending herniation due to a large parenchymal lesion. 


\section{Pregnancy and Contraception}

CSVT occurrence during pregnancy or puerperium is not a contraindication for future pregnancies [10]. CSVT occurring during these periods should be treated with LMWH and continued through 6 weeks of postpartum. All forms of hormonal contraception except progesterone-only therapies should be stopped in patients who develop CSVT with OCP or hormone replacement therapy. Other forms of contraception can be used as an alternative in these patients.

\section{Treatment of Underlying Risk Factors}

A thorough diagnostic evaluation to identify underlying etiological factors followed by proper treatment is essential in the management of CSVT.

- Antibiotics for sepsis and other intra- and extracranial infections.

- Chemotherapy should be given as recommended for specific cancers.

- Stop all hormonal therapy like oral contraceptive pills and hormone replacement therapy. Progesteronecontaining treatments can be used [10].

- Steroids are recommended in patients with acute CSVT and Behcet's disease, vasculitis, or other inflammatory diseases like systemic lupus erythematosus [52].

\section{Outcomes}

The predictors of acute mortality were transtentorial herniation resulting from raised ICP, status epilepticus, and underlying comorbidities. Predictors of mortality at 30 days were depressed consciousness, altered mental status, thrombosis of the deep venous system, right hemisphere hemorrhage, and posterior fossa lesions [60]. A systematic review that studied the natural course of CSVT found a mortality rate of $5.6 \%$ in the acute phase and $9.4 \%$ at the end of follow-up. The study also found that complete or partially complete recovery (mild cognitive and functional deficits) was seen in $88 \%$ of cases, and the recurrence rate was $2.8 \%$ [63]. Headache is the most common complaint that is encountered during the follow-up of a CVT patient, which, if persistent, can raise the concerns of recurrence. It should be evaluated with neuroimaging (CT/MRI) and LP if necessary [10]. Patients with CSVT have an increased risk of developing CSVT recurrence in about one-third of cases or other forms of VTE. In these cases, thrombophilic states should be ruled out with appropriate diagnostic modalities [32]. Markers for worse long-term prognosis include male sex, intracranial hemorrhage on imaging, infectious or malignant etiology, altered mental status and/or Glasgow Coma Scale $<9$, and thrombosis of the deep cerebral venous system [6, 12].

\section{Conclusion}

CSVT is a rare form of stroke that often affects younger age-groups, especially reproductive age-group females. The clinical presentation is variable with headache being the most common presenting symptom, and a high index of clinical suspicion is required for detecting affected individuals. The diagnosis is predominantly using a CTV/ MRI/MRV and cerebral angiography if other imaging modalities fail. Anticoagulation with LMWH is the mainstay of the treatment, and endovascular thrombolysis is still controversial. Intracranial hemorrhage is not considered a contraindication to the use of anticoagulants in CVT. Patients with CVT have an increased risk of recurrence of CVT and other VTEs.

\section{Future Research}

There is still a lot of research required to fully understand the natural course of CVT, which will further aid with the diagnosis and management of the disease. Future studies are required to understand the epidemiology and etiological risk factors due to the rarity of the disease. Newer diagnostic techniques are essential, and large-scale comparative studies of existing imaging techniques are required. Large randomized control trials are required for providing stronger evidence for the various therapeutic interventions of CVT. Further studies are required that compare the different therapies to help aid better treatment to patients with CVT because of increased mortality rates.

\section{Acknowledgements}

The authors would like to thank Deanship of Scientific Research at Majmaah University for supporting this work under project number R-1441-96.

\section{Statement of Ethics}

The authors have no conflicts of interest to declare. 


\section{Conflict of Interest Statement}

The authors declare that they have no conflict of interests.

\section{Funding Sources}

Deanship of Scientific Research at Majmaah University, under project number R-1441-96.

\section{Author Contributions}

All authors have been involved in the preparation of this manuscript. All authors have read and approved the manuscript. The corresponding author has full access to data and has the right to publish this data.

\section{References}

1 Alvis-Miranda HR, Milena Castellar-Leones S, Alcala-Cerra G, Rafael Moscote-Salazar L. Cerebral sinus venous thrombosis. J Neurosci Rural Pract. 2013;4(4):427-38.

2 Guenther G, Arauz A. Cerebral venous thrombosis: a diagnostic and treatment update. Neurologia. 2011;26(8):488-98.

3 Ferro JM, Canhão P. Cerebral venous sinus thrombosis: update on diagnosis and management. Curr Cardiol Rep. 2014;16(9):523.

4 Bousser MG, Ferro JM. Cerebral venous thrombosis: an update. Lancet Neurol. 2007; 6(2):162-70.

5 Saposnik G, Barinagarrementeria F, Brown RD Jr, Bushnell CD, Cucchiara B, Cushman $M$, et al. Diagnosis and management of cerebral venous thrombosis: a statement for healthcare professionals from the American Heart Association/American Stroke Association. Stroke. 2011;42(4):1158-92.

6 Ferro JM, Canhão P, Stam J, Bousser MG Barinagarrementeria F. Prognosis of cerebral vein and dural sinus thrombosis: results of the International Study on Cerebral Vein and Dural Sinus Thrombosis (ISCVT). Stroke. 2004;35(3):664-70.

7 Zivadinov R, Chung CP. Potential involvement of the extracranial venous system in central nervous system disorders and aging. BMC Med. 2013;11:260.

8 Dmytriw AA, Song JSA, Yu E, Poon CS. Cerebral venous thrombosis: state of the art diagnosis and management. Neuroradiology. 2018 Jul;60(7):669-85.

9 Meder JF, Chiras J, Roland J, Guinet P, Bracard S, Bargy F. Venous territories of the brain. J Neuroradiol. 1994;21(2):118-33.

10 Ferro JM, Canhão P, Aguiar de Sousa D. Cerebral venous thrombosis. Presse Med. 2016 Dec;45(12 Pt 2):e429-50.

11 Coutinho JM, Ferro JM, Canhão P, Barinagarrementeria F, Cantú C, Bousser MG, et al. Cerebral venous and sinus thrombosis in women. Stroke. 2009;40(7):2356-61.

12 Ferro JM, Canhão P, Bousser MG, Stam J, Barinagarrementeria F, Investigators I. Cerebral vein and dural sinus thrombosis in elderly patients. Stroke. 2005;36(9):1927-32.

13 deVeber G, Andrew M, Adams C, Bjornson B, Booth F, Buckley DJ, et al. Cerebral sinovenous thrombosis in children. N Engl J Med. 2001;345(6):417-23.
14 Dentali F, Crowther M, Ageno W. Thrombophilic abnormalities, oral contraceptives, and risk of cerebral vein thrombosis: a meta-analysis. Blood. 2006;107(7):2766-73.

15 Zuurbier SM, Arnold M, Middeldorp S, Broeg-Morvay A, Silvis SM, Heldner MR, et al. Risk of cerebral venous thrombosis in obese women. JAMA Neurol. 2016;73(5): 579-84.

16 de Bruijn SF, Stam J, Koopman MM, Vandenbroucke JP. Case-control study of risk of cerebral sinus thrombosis in oral contraceptive users and in [correction of who are] carriers of hereditary prothrombotic conditions. The Cerebral Venous Sinus Thrombosis Study Group. BMJ. 1998;316(7131):589-92.

17 Sidhom Y, Mansour M, Messelmani M, Derbali H, Fekih-Mrissa N, Zaouali J, et al. Cerebral venous thrombosis: clinical features, risk factors, and long-term outcome in a Tunisian cohort. J Stroke Cerebrovasc Dis. 2014;23(6): 1291-5.

18 Korathanakhun P, Petpichetchian W, Sathirapanya $\mathrm{P}$, Geater SL. Cerebral venous thrombosis: comparing characteristics of infective and non-infective aetiologies: a 12-year retrospective study. Postgrad Med J. 2015; 91(1082):670-4.

19 Grisold W, Oberndorfer S, Struhal W. Stroke and cancer: a review. Acta Neurol Scand. 2009;119(1):1-16.

20 Giladi O, Steinberg DM, Peleg K, Tanne D, Givon A, Grossman E, et al. Head trauma is the major risk factor for cerebral sinus-vein thrombosis. Thromb Res. 2016;137:26-9.

21 Schaller B, Graf R. Cerebral venous infarction: the pathophysiological concept. Cerebrovasc Dis. 2004;18(3):179-88.

22 Long B, Koyfman A, Runyon MS. Cerebral venous thrombosis: a challenging neurologic diagnosis. Emerg Med Clin North Am. 2017 Nov;35(4):869-78.

23 Röttger C, Bachmann G, Gerriets T, Kaps M, Kuchelmeister K, Schachenmayr W, et al. A new model of reversible sinus sagittalis superior thrombosis in the rat: magnetic resonance imaging changes. Neurosurgery. 2005; 57(3):573-80

24 Ungersböck K, Heimann A, Kempski O. Cerebral blood flow alterations in a rat model of cerebral sinus thrombosis. Stroke. 1993;24(4): $563-70$.
25 Ueda K, Nakase H, Miyamoto K, Otsuka H, Sakaki T. Impact of anatomical difference of the cerebral venous system on microcirculation in a gerbil superior sagittal sinus occlusion model. Acta Neurochir. 2000;142(1):7582.

26 Gotoh M, Ohmoto T, Kuyama H. Experimental study of venous circulatory disturbance by dural sinus occlusion. Acta Neurochir. 1993; 124(2-4):120-6.

27 Bousser MG, Ross Russell R. Cerebral venous thrombosis. London: WB Saunders; 1997. Vol. 1.

28 Cumurciuc R, Crassard I, Sarov M, Valade D, Bousser MG. Headache as the only neurological sign of cerebral venous thrombosis: a series of 17 cases. J Neurol Neurosurg Psychiatry. 2005;76(8):1084-7.

29 Timóteo Â, Inácio N, Machado S, Pinto AA, Parreira E. Headache as the sole presentation of cerebral venous thrombosis: a prospective study. J Headache Pain. 2012;13(6): 487-90.

30 Heckmann JG, Schüttler M, Tomandl B Achard-Lévi syndrome: pupil-sparing oculomotor nerve palsy due to midbrain stroke. Cerebrovasc Dis. 2003;16(1):109-10.

31 Teichgraeber JF, Per-Lee JH, Turner JS. Lateral sinus thrombosis: a modern perspective. Laryngoscope. 1982;92(7 Pt 1):744-51.

32 Turner SE, Parry-Jones AR, Punter M, Hurford R, Thachil J. Cerebral venous thrombosis-a primer for the haematologist. Blood Rev. 2015;29(1):45-50.

33 Stam J. Thrombosis of the cerebral veins and sinuses. N Engl J Med. 2005;352(17):1791-8.

34 Masuhr F, Busch M, Amberger N, Ortwein H, Weih M, Neumann K, et al. Risk and predictors of early epileptic seizures in acute cerebral venous and sinus thrombosis. Eur J Neurol. 2006;13(8):852-6.

35 Kothare SV, Ebb DH, Rosenberger PB, Buonanno F, Schaefer PW, Krishnamoorthy KS. Acute confusion and mutism as a presentation of thalamic strokes secondary to deep cerebral venous thrombosis. I Child Neurol. 1998;13(6):300-3.

36 Canhão P, Abreu LF, Ferro JM, Stam J, Bousser MG, Barinagarrementeria F, et al. Safety of lumbar puncture in patients with cerebral venous thrombosis. Eur J Neurol. 2013;20(7): 1075-80. 
37 Tanislav C, Siekmann R, Sieweke N, Allendörfer J, Pabst W, Kaps M, et al. Cerebral vein thrombosis: clinical manifestation and diagnosis. BMC Neurol. 2011;11:69.

38 van Dam LF, van Walderveen MAA, Kroft LJM, Kruyt ND, Wermer MJH, van Osch MJP, et al. Current imaging modalities for diagnosing cerebral vein thrombosis: a critical review. Thromb Res. 2020 Mar 19;189:132-9.

39 Coutinho JM, van den Berg R, Zuurbier SM, VanBavel E, Troost D, Majoie CB. et al. Small juxtacortical hemorrhages in cerebral venous thrombosis. Ann Neurol. 2014;75(6):908-16.

40 Rodallec MH, Krainik A, Feydy A, Hélias A, Colombani JM, Jullès MC, et al. Cerebral venous thrombosis and multidetector CT angiography: tips and tricks. Radiographics. 2006 Oct;26(Suppl 1):S5-3.

41 Linn J, Michl S, Katja B, Pfefferkorn T, Wiesmann M, Hartz S, et al. Cortical vein thrombosis: the diagnostic value of different imaging modalities. Neuroradiology. 2010;52(10): 899-911.

42 Leach JL, Fortuna RB, Jones BV, Gaskill-Shipley MF. Imaging of cerebral venous thrombosis: current techniques, spectrum of findings, and diagnostic pitfalls. Radiographics. 2006;26(Suppl 1):S19-3.

43 Bergui M, Bradac GB. Clinical picture of patients with cerebral venous thrombosis and patterns of dural sinus involvement. Cerebrovasc Dis. 2003;16(3):211-6.

44 Idbaih A, Boukobza M, Crassard I, Porcher R, Bousser MG, Chabriat H. MRI of clot in cerebral venous thrombosis: high diagnostic value of susceptibility-weighted images. Stroke. 2006;37(4):991-5.

45 Hinman JM, Provenzale JM. Hypointense thrombus on T2-weighted MR imaging: a potential pitfall in the diagnosis of dural sinus thrombosis. Eur J Radiol. 2002;41(2):147-52.
46 Boukobza M, Crassard I, Bousser MG, Chabriat $\mathrm{H}$. MR imaging features of isolated cortical vein thrombosis: diagnosis and follow-up. AJNR Am J Neuroradiol. 2009;30(2):344-8.

47 Ganeshan D, Narlawar R, McCann C, Jones HL, Curtis J. Cerebral venous thrombosis-A pictorial review. Eur J Radiol. 2010;74(1): $110-6$.

48 Linn J, Ertl-Wagner B, Seelos KC, Strupp M, Reiser M, Brückmann H, et al. Diagnostic value of multidetector-row CT angiography in the evaluation of thrombosis of the cerebral venous sinuses. AJNR Am J Neuroradiol. 2007;28(5);946-52.

49 De Bruijn SFTM, Stam J; for the Cerebral Venous Sinus Thrombosis Study Group. Randomized, placebo-controlled trial of anticoagulant treatment with low-molecular-weight heparin for cerebral sinus thrombosis. Stroke. 1999;30(3):484-8.

50 Stam KM, Villringer A, Meister,W, Mehraein S, Garner C, Pellkofer M, et al. Heparin treatment in sinus venous thrombosis. Lancet. 1991;338(8767):597-600.

51 Stam J, de Bruijn SFTM, deVeber G. Anticoagulation for cerebral venous sinus thrombosis. Cochrane Database Syst Rev. 2001:4(8): CD002005.

52 Stam JM, Bousser MG, Canhão P, Coutinho JM, Crassard I, Dentali F, et al. European Stroke Organization guideline for the diagnosis and treatment of cerebral venous thrombosis: endorsed by the European Academy of Neurology. Eur J Neurol. 2017;24(10):120313.

53 Dentali F, Squizzato A, Gianni M, De Lodovici ML, Venco A, Paciaroni M, et al. Safety of thrombolysis in cerebral venous thrombosis. A systematic review of the literature. Thromb Haemost. 2010;104(5):1055-62.

54 Coutinho JM, Ferro JM, Zuurbier SM, Mink MS, Canhão P, Crassard I, et al. Thrombolysis or anticoagulation for cerebral venous thrombosis: rationale and design of the TO-ACT trial. Int J Stroke. 2013;8(2):135-40.
55 Tait C, Baglin T, Watson H, Laffan M, Makris $\mathrm{M}$, Perry D, et al. Guidelines on the investigation and management of venous thrombosis at unusual sites. Br J Haematol. 2012;159(1): 28-38.

56 Breteau G, Mounier-Vehier F, Godefroy O, Gauvrit JY, Mackowiak-Cordoliani MA, Girot $\mathrm{M}$, et al. Cerebral venous thrombosis 3 -year clinical outcome in 55 consecutive patients. J Neurol. 2003;250(1):29-35.

57 Ferro JM, Correia M, Rosas MJ, Pinto AN, Neves G. Seizures in cerebral vein and dural sinus thrombosis. Cerebrovasc Dis. 2003; 15(1-2):78-83.

58 Neves JM, Canhão P, Bousser MG, Stam J, Barinagarrementeria F. Early seizures in cerebral vein and dural sinus thrombosis: risk factors and role of antiepileptics. Stroke. 2008; 39(4):1152-8.

59 Kalita J, Chandra S, Misra UK. Significance of seizure in cerebral venous sinus thrombosis. Seizure. 2012;21(8):639-42.

60 Canhão P, Ferro JM, Lindgren AG, Bousser MG, Stam J, Barinagarrementeria $\mathrm{F}$, et al. Causes and predictors of death in cerebral venous thrombosis. Stroke. 2005;36(8);1720-5.

61 Wall M, McDermott MP, Kieburtz KD, Corbett JJ, Feldon SE. Effect of acetazolamide on visual function in patients with idiopathic intracranial hypertension and mild visual loss: the idiopathic intracranial hypertension treatment trial. JAMA. 2014;311(16):16411651.

62 Einhäupl K, Stam J, Bousser MG, De Bruijn SF, Ferro JM, Martinelli I, et al. EFNS guideline on the treatment of cerebral venous and sinus thrombosis in adult patients. Eur J Neurol. 2010;17(10):1229-35.

63 Dentali F, Gianni M, Crowther MA, Ageno W. Natural history of cerebral vein thrombosis: a systematic review. Blood. 2006;108(4): 1129-34. 